\title{
Introduction to special issue: mobile business and information systems
}

\author{
Norm Archer
}

Published online: 15 October 2008

(C) Springer-Verlag 2008

The articles in this special issue are major extensions and revisions of some of the best conference papers that were presented at the Sixth International Conference on Mobile Business ${ }^{1}$, organized by the McMaster University eBusiness Research Centre and held in Toronto, Canada in July 2007. These papers cover a number of highly relevant aspects of mobile business and related applications.

The first paper in this issue, by Goetz Botterweck, J. Felix Hampe, Stefan Stein, and Andreas Rosendahl addresses mobile home automation, involving the integration of mobile application platforms and home automation technologies. Through a two-dimensional mobility model, the authors review home automation services from the user perspective and tie this into a general system architecture for design decisions. Their proposed design is implemented and demonstrated through a research prototype.

In the next paper, Harry Bouwman, Christer Carlsson, Pirkko Walden, and Francisco J Molina-Castillo use the experience of Finland, which has arguably the highest penetration of mobile handset use in the world, to examine trends in service adoption over a 3-year period. They tested models in which innovativeness, flexibility, status, and entertainment value were related to applications of mobile services, concluding that characteristics and user values of mobile services must be considered in order to understand current use and to predict future use.

Håkon Ursin Steen's paper examines the complex world of standards wars as different standards compete for dominance as radio carriers during the development of mobile digital broadcasting. This study draws on insights from multi-sided market theory and structural constraints that influence the selection and stabilization

\footnotetext{
1 Available in ICMB 2007 International Conference on Mobile Business (IEEE).
}

N. Archer $(\bowtie)$

DeGroote School of Business, McMaster University, Hamilton L8S 4M4, Canada

e-mail: archer@mcmaster.ca 
of standards. In particular, the paper examines standards fragmentation and its potential outcomes and implications in the multi-national marketplace.

Finally, there are two papers on mobile payments. The first, by Jan Ondrus and Yves Pigneur, uses multi-criteria analysis to assess in a systematic manner the potential of Near Field Communications (NFC) in the payment marketplace. For their study, they selected all the major companies dealing with mobile payments in Switzerland, and contacted the key experts and decision makers in these companies that deal with relevant mobile payments issues. Although their assessment of NFC through these experts shows encouraging results, there are still many technical and business issues to be solved.

In the second paper on mobile payments, Key Pousttchi, Max Schiessler, and Dietmar G Wiedemann point out that any remaining technical hurdles for mobile payment systems are minor. However, a continuing failure of mobile payments approaches can be explained by the high interdependency of technical, human and market factors which have to be addressed cohesively to solve the problem. They use a Business Model Ontology to develop a Mobile Payment Business Model Framework that was derived from a multiple case study of 27 mobile payment procedures. The resulting framework enables researchers and practitioners to do a comprehensive analysis of existing and future models that will help in engineering m-payment business models. 